J Neurovirol. 2013 June ; 19(3): 270-273. doi:10.1007/s13365-013-0164-z.

\title{
Susac syndrome in a patient with human immunodeficiency virus infection
}

\author{
Erin E. Longbrake, \\ Department of Neurology, Washington University in Saint Louis, Saint Louis, MO, USA \\ Beau M. Ances, \\ Department of Neurology, Washington University in Saint Louis, Saint Louis, MO, USA \\ Hope Center, Washington University in Saint Louis, Saint Louis, MO, USA
}

Ryan B. Viets, and

Mallinckrodt Institute of Radiology, Washington University in Saint Louis, Saint Louis, MO, USA

David B. Clifford

Department of Neurology, Washington University in Saint Louis, Saint Louis, MO, USA

Department of Neurology, Washington University School of Medicine, 660 South Euclid Ave., Campus Box 8111, St. Louis, MO 63110, USA

David B. Clifford: cliffordd@neuro.wustl.edu

\section{Introduction}

Susac syndrome (SS) is a diagnosis of exclusion based on findings of encephalopathy, branch retinal artery occlusions (BRAO), and hearing loss (Susac et al. 1979). These components may occur simultaneously or be temporally separated. The diagnosis is strongly supported by pathognomic involvement of the body of the corpus callosum on MRI; deep gray matter lesions, gadolinium enhancing lesions, and leptomeningeal enhancement may also be seen (Susac et al. 2003).

\section{Case report}

A 22-year-old previously healthy man presented to the emergency department complaining of confusion. He was a successful college student and athletic trainer, but his performance had deteriorated over 3 weeks. In the emergency department, he was lethargic and disoriented. He had no allergies and was not taking medication. He drank socially, denied tobacco or drug use, and was sexually active with multiple partners.

At admission, CSF analysis showed four nucleated cells, glucose of $73 \mathrm{mg} / \mathrm{dL}$, and protein of $196 \mathrm{mg} / \mathrm{dL}$; there were no oligoclonal bands. CSF testing for HSV, enterovirus, West Nile virus, arbovirus antibodies, encephalitis antibodies (against measles, mumps, LCM virus),

Correspondence to: David B. Clifford, cliffordd@neuro . wustl . edu. 
VDRL, and routine/fungal cultures was negative. Blood studies including serum protein electrophoresis, erythrocyte sedimentation rate, antinuclear antibodies, and thyroid hormones were normal. HIV testing was positive and CD4 count was $266 \mathrm{cells} / \mathrm{mm}^{3}$. MRI revealed multiple white matter lesions involving the corpus callosum, bilateral cerebral and cerebellar hemispheres, deep gray matter, and brainstem with leptomeningeal enhancement (Fig. 1a-c). He was presumptively diagnosed with HIV encephalitis and started on antiretrovirals (lamivudine, lopinavir/ritonavir, and zidovudine). Two weeks later, his CD4 count had increased to 359 cells $/ \mathrm{mm}^{3}$ and his viral load was 555 copies $/ \mathrm{mm}^{3}$. His cognitive impairment remained disabling. Formal neuropsychological testing after 2 months revealed moderate to severe anterograde amnesia with additional deficits in information processing speed, executive control, and working memory. These deficits were more profound than expected, given that his HIV disease was not advanced either by viral load or CD4 measures. Six months later, repeat testing documented dramatic improvements in memory, motor functioning, word finding, and attention. Deficits in memory and information processing speed persisted.

Two years after his sentinel event, he developed sudden unilateral vision loss and multiple BRAO were identified via fluorescein angiography (Fig. 2). Transesophageal echocardiogram, CSF studies, cerebral MRI/MRA, and rheumatologic/hypercoagulable blood studies revealed no etiology. He was started on anticoagulation for a presumed cryptogenic hypercoagulable state.

Six years after his presentation, he developed sudden unilateral deafness with tinnitus. CSF analysis and rheumatologic/hypercoagulable testing were again normal; MRI was unchanged. His CD4 count was 403 cells $/ \mathrm{mm}^{3}$ and viral load was undetectable. Audiology revealed severe sensorineural hearing loss, more pronounced at lower frequencies. SS was diagnosed given the triad of encephalopathy, BRAO, and hearing loss in conjunction with typical MRI findings at presentation. No chronic immunosuppression was initiated, given his underlying HIV. HIV control has been excellent since diagnosis, but he has persistent cognitive, visual, and hearing impairments due to SS.

\section{Discussion}

Biopsy data suggest that SS is a microangiopathy (Rennebohm and Susac 2007). Infectious, hypercoagulable, and vascular etiologies have been hypothesized (Dorr et al. 2009); current data suggest that it is an autoimmune endotheliopathy that affects the retina, cochlea, and brain. SS has been linked to anti-endothelial cell antibodies (Jarius et al. 2009; Magro et al. 2011), although it is unclear whether these are pathogenic. Anti-endothelial antibody testing is not yet commercially available and was not obtained on this patient. SS is typically treated by aggressive immunosuppression, although there is no standardized regimen (Rennebohm and Susac 2007). Because the disease course varies from monophasic and self-limited (Gordon et al. 1991) to polyphasic and relapsing (Dorr et al. 2009; Rennebohm and Susac 2007), it becomes difficult to determine an appropriate duration for immunosuppressive treatment. 
To our knowledge, this is the first published report of SS in a patient with concurrent HIV, though a similar patient was presented in abstract form in Vryonis et al. 2011. SS was not considered until late in this case, as the presentation was attributed to HIV encephalopathy. His symptoms were far more severe than expected given his degree of immunosuppression, however, and neither the elevated CSF protein nor the MR pattern of involvement suggested HIV-associated brain disease. Indeed, while HIV cognitive impairment may involve the corpus callosum, changes within only the central portion are rare (Kieburtz et al. 1990). This report of coincident SS and HIV may shed light on the pathogenesis of SS, which is likely an autoimmune disease (Magro et al. 2011). Interestingly, other presumed autoimmune disorders such as Guillian-Barre syndrome, polymyositis, and dermatomyositis may present early in HIV disease, and autoantibodies are frequently detected in HIV patients (Brannagan and Zhou 2003; Carroll and Holmes 2011; Rajadhyaksha et al. 2012; Zandman-Goddard and Shoenfeld 2002), suggesting that these individuals, though relatively immunosuppressed, are not invulnerable to autoimmune diseases. This case should raise awareness of SS as an etiology for encephalopathy and white matter changes even in patients with comorbid HIV.

\section{Acknowledgments}

The authors would like to thank Dr. Gregory Van Stavern for providing fluorescein angiography images.

Dr. Clifford serves on Data Safety Boards for Amgen, Biogen, GSK, Millennium, Genzyme, Genentech, and Pfizer. He has been a consultant to Amgen, Brinker, Biddle, Reath (PML Consortium), Genentech, Genzyme, BristolMyers Squibb, Millennium, Biogen Idec, and Pfizer. He has received research support from Bavarian Nordic, Biogen Idec, Lilly, NeurogesX, Tibotec, Pfizer, and Roche. He has received speaking fees from the University of Kentucky and CMSC/ACTRIMS.

\section{References}

Brannagan TH 3rd, Zhou Y. HIV-associated Guillain-Barre syndrome. J Neurol Sci. 2003; 208:39-42. [PubMed: 12639723]

Carroll MB, Holmes R. Dermatomyositis and HIV infection: case report and review of the literature. Rheumatol Int. 2011; 31:673-679. [PubMed: 19855968]

Dorr J, Radbruch H, Bock M, Wuerfel J, Bruggemann A, Wandinger KP, Zeise D, Pfueller CF, Zipp F, Paul F. Encephalopathy, visual disturbance and hearing loss-recognizing the symptoms of Susac syndrome. Nat Rev Neurol. 2009; 5:683-688. [PubMed: 19953118]

Gordon DL, Hayreh SS, Adams HP Jr. Microangiopathy of the brain, retina, and ear: improvement without immunosuppressive therapy. Stroke. 1991; 22:933-937. [PubMed: 1853414]

Jarius S, Neumayer B, Wandinger KP, Hartmann M, Wildemann B. Anti-endothelial serum antibodies in a patient with Susac's syndrome. J Neurol Sci. 2009; 285:259-261. [PubMed: 19643446]

Kieburtz KD, Ketonen L, Zettelmaier AE, Kido D, Caine ED, Simon JH. Magnetic resonance imaging findings in HIV cognitive impairment. Arch Neurol. 1990; 47:643-645. [PubMed: 2346391]

Magro CM, Poe JC, Lubow M, Susac JO. Susac syndrome: an organ-specific autoimmune endotheliopathy syndrome associated with anti-endothelial cell antibodies. Am J Clin Pathol. 2011; 136:903-912. [PubMed: 22095376]

Rajadhyaksha A, Baheti TG, Mehra S, Sonawale AS, Jain N. Dermatomyositis: a rare presentation of HIV seroconversion illness. J Clin Rheumatol. 2012; 18:298-300. [PubMed: 22955479]

Rennebohm RM, Susac JO. Treatment of Susac's syndrome. J Neurol Sci. 2007; 257:215-220. [PubMed: 17324441]

Susac JO, Hardman JM, Selhorst JB. Microangiopathy of the brain and retina. Neurology. 1979; 29:313-316. [PubMed: 571975] 
Susac JO, Murtagh FR, Egan RA, Berger JR, Bakshi R, Lincoff N, Gean AD, Galetta SL, Fox RJ, Costello FE, Lee AG, Clark J, Layzer RB, Daroff RB. MRI findings in Susac's syndrome. Neurology. 2003; 61:1783-1787. [PubMed: 14694047]

Vryonis E, Kakalou E, Baxevanakis A, Linardi C, Papanikolaou K, Papastamopoulos V, Baraboutis I, Skoutelis A. P2180 Susac's syndrome in a HIV-infected patient. Clin Microbiol Inf. 2011; 17(suppl 4):S651.

Zandman-Goddard G, Shoenfeld Y. HIV and autoimmunity. Autoimmun Rev. 2002; 1:329-337. [PubMed: 12848988] 


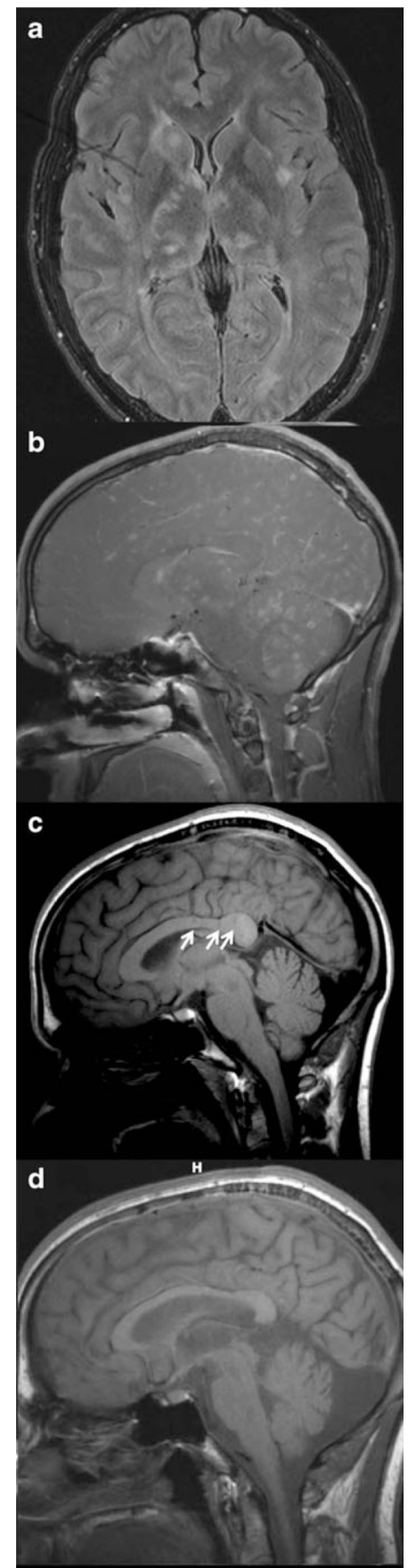

Fig. 1.

MRI findings in a patient with Susac syndrome and acute HIV. MR images at initial presentation (a-c) and after 2.5 years $(\mathbf{d})$. Axial T2 FLAIR image demonstrates typical ovoid T2 hyperintensities within both thalami, the right caudate head, and the left putamen, as well as the genu of the corpus callosum (a). Post-contrast sagittal T1 image reveals multiple enhancing parenchymal lesions as well as predominantly posterior leptomeningeal enhancement (b). Pre-contrast sagittal T1 image demonstrates central hypointensities (central holes) within the corpus callosum (c). Repeat pre-contrast T1 sagittal image 2.5 
years later demonstrates marked interval atrophy of the corpus callosum with stable central callosal hypointensities $(\mathbf{d})$. 


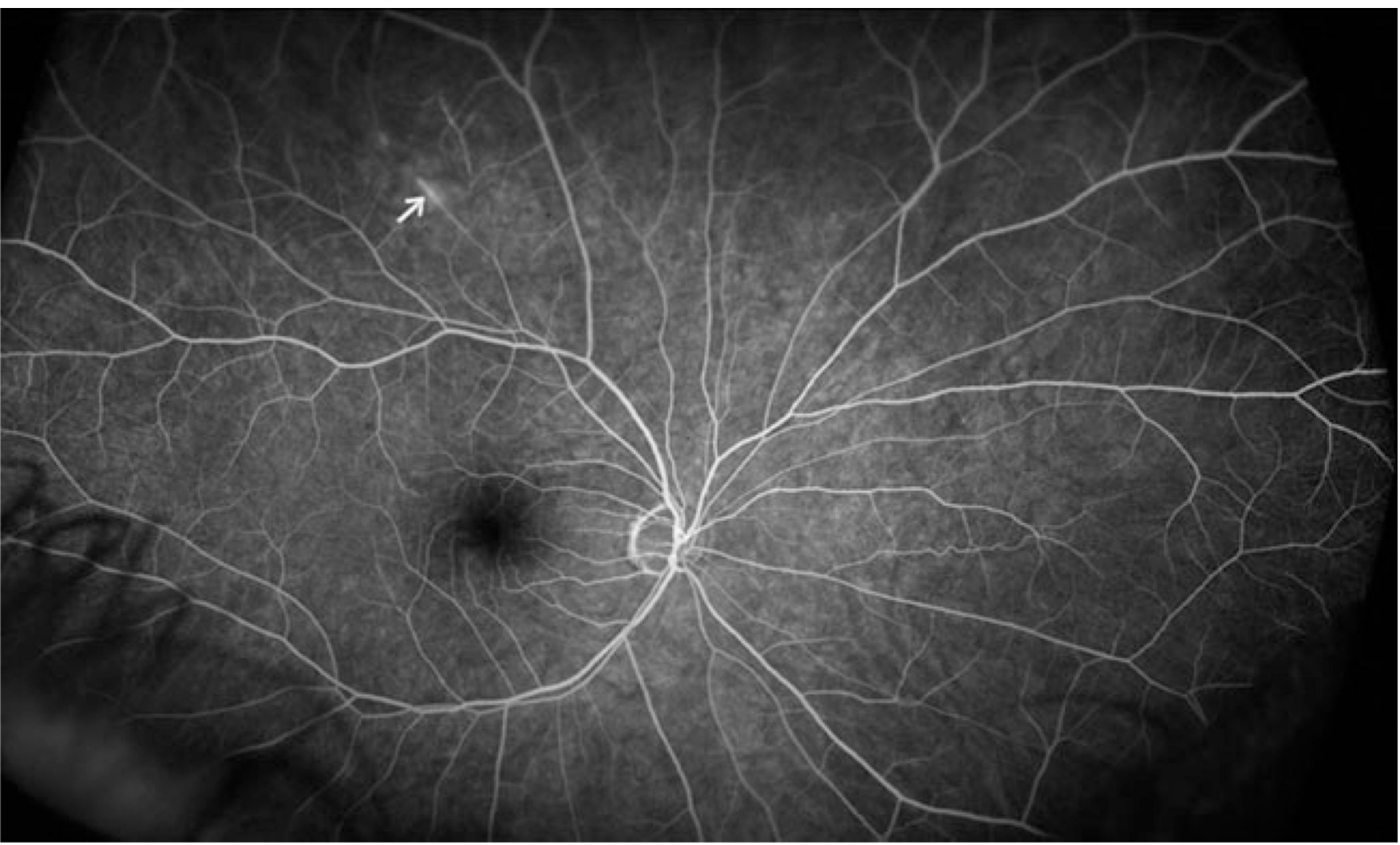

Fig. 2.

Retinal damage in a patient with Susac Syndrome. Follow-up fluorescein angiogram performed 1 month after an acute BRAO demonstrated resolution of occlusion but continued foci of retinal hyperfluorescence (arrow) indicative of active endothelial damage 